\title{
The dual origin of the peripheral olfactory system: placode and neural crest
}

\author{
Hiroyuki Katoh ${ }^{1,2}$, Shinsuke Shibata ${ }^{2}$, Kimiko Fukuda ${ }^{3}$, Momoka Sato $^{2}$, Etsuko Satoh², Narihito Nagoshi ${ }^{1,2,5}$, \\ Takeo Minematsu4 ${ }^{4}$, Yumi Matsuzaki ${ }^{2}$, Chihiro Akazawa ${ }^{6}$, Yoshiaki Toyama', Masaya Nakamura' and \\ Hideyuki Okano ${ }^{2^{*}}$
}

\begin{abstract}
Background: The olfactory epithelium (OE) has a unique capacity for continuous neurogenesis, extending axons to the olfactory bulb with the assistance of olfactory ensheathing cells (OECs). The OE and OECs have been believed to develop solely from the olfactory placode, while the neural crest (NC) cells have been believed to contribute only the underlying structural elements of the olfactory system. In order to further elucidate the role of NC cells in olfactory development, we examined the olfactory system in the transgenic mice Wnt1-Cre/Floxed-EGFP and PO-Cre/Floxed-EGFP, in which migrating NC cells and its descendents permanently express GFP, and conducted transposon-mediated cell lineage tracing studies in chick embryos.

Results: Examination of these transgenic mice revealed GFP-positive cells in the OE, demonstrating that NCderived cells give rise to OE cells with morphologic and antigenic properties identical to placode-derived cells. OECs were also positive for GFP, confirming their NC origin. Cell lineage tracing studies performed in chick embryos confirmed the migration of NC cells into the OE. Furthermore, spheres cultured from the dissociated cells of the olfactory mucosa demonstrated self-renewal and trilineage differentiation capacities (neurons, glial cells, and myofibroblasts), demonstrating the presence of NC progenitors in the olfactory mucosa.
\end{abstract}

Conclusion: Our data demonstrates that the NC plays a larger role in the development of the olfactory system than previously believed, and suggests that NC-derived cells may in part be responsible for the remarkable capacity of the OE for neurogenesis and regeneration.

Keywords: neural crest, olfactory placode, olfactory ensheathing cell, neural crest progenitor cell, PO-Cre, Wnt1-Cre, Sox10, chick embryo

\section{Background}

The sensory organs of the vertebrate head derive from two embryological structures, the sensory placodes and the cranial neural crest $(\mathrm{NC})$, which arise from the border between neural and non-neural ectoderms on the lateral edge of the neural plate and contribute to the formation of the peripheral sensory nervous system in an intricate relationship during cranial development. Placodes are discrete areas of thickened non-neural epithelium that form in characteristic positions in the head of vertebrate embryos and give rise to the paired

\footnotetext{
* Correspondence: hidokano@a2.keio.jp

${ }^{2}$ Department of Physiology, Keio University School of Medicine, 35

Shinanomachi, Shinjuku-ku, Tokyo, 160-8582, Japan

Full list of author information is available at the end of the article
}

sensory organs, including the olfactory system. The NC is a multipotent population of migratory cells unique to the vertebrate embryo that delaminate from the neural epithelium and migrate throughout the embryo to give rise to a wide variety of cell types [1,2].

The olfactory organ has been shown to arise from a combination of the olfactory placode and cranial NC cells, with the olfactory placode giving rise to the olfactory sensory neurons and supporting cells of the olfactory epithelium (OE) [3-5], and the NC contributing to the structural elements of the nose. The role of the olfactory placode in olfactory development was first experimentally demonstrated in the early twentieth century when resection of the olfactory placode in amphibians was shown to disrupt the development of

\section{Biomed Central}


the olfactory bulb [6]. Cell labeling and olfactory placode ablation experiments later verified that the $\mathrm{OE}$ develops from the olfactory placode. However it is important to note that many of these analyses were conducted in developmental stages after olfactory placode formation, and thus after anterior migration of the cranial NC cells. By the time that the placode has formed, $\mathrm{NC}$ cells contributing to the frontal mass have migrated anteriorly and are intimately associated with the olfactory placode. Any manipulations conducted to the olfactory placode at this stage will also affect the underlying NC cells that play an important role in olfactory development. The importance of NC cells in the development of the olfactory system was demonstrated in rSey rats with a mutation in the Pax6 gene in which impaired migration of midbrain crest cells into the frontonasal mass led to the loss of the nasal placode [7], and retinoic acid signaling from $\mathrm{NC}$ cells was found to be necessary for olfactory placode development [8]. The convergence of placode and $\mathrm{NC}$ cells in the embryo to give rise to the olfactory organ has made uncovering the developmental origins of the olfactory components very complicated.

However with the advancement of transgenic animal techniques, it has become possible to permanently label early presumptive $\mathrm{NC}$ cells and all subsequent progeny by using a double transgenic system. The first component is a transgene expressing Cre recombinase driven by promoters/enhancers of either Wnt1 or myelin protein zero (P0). The Wnt1 gene is expressed specifically in the neural plate, in the dorsal neural tube, and in the early migratory NC population. In NC cells, Wnt1 expression in extinguished as the cells migrate away from the neural tube, and is not expressed at any other time or place [9]. The P0 glycoprotein is a cell adhesion molecule that constitutes the myelin sheaths in the peripheral nervous system $[10,11]$, and its mRNA has been demonstrated to be expressed in a subpopulation of NC cells after detachment from the neuroepithelium $[12,13]$. The second component is a reporter gene that is expressed only upon Cre-mediated recombination [14]. By observing the olfactory system in these transgenic mice, we were able to distinguish between $\mathrm{NC}$-derived and olfactory placode-derived components, thus identifying the tissue origins of the olfactory organ.

In order to confirm the findings observed in the transgenic mice, we conducted cell tracing studies of $\mathrm{NC}$ cells in chick embryos. The in ovo electroporation in chick embryos has widely been used as a powerful tool to study roles of genes during embryogenesis. However, the conventional electroporation technique fails to retain the expression of transgenes for more than several days because transgenes are not integrated into the genome. To overcome this shortcoming, we utilized a transposon-mediated gene transfer method [15] and were able to observe reporter gene expression until embryonic day 13.

Examination of the olfactory system in the transgenic mice and chick embryos have revealed that NC-derived cells play a significantly larger role in olfactory development than was previously believed. Here, we demonstrate that NC-derived cells are present in both embryonic and postnatal OE with morphology and antigenic profiles that are indistinguishable from placodederived epithelial cells, and confirm that olfactory ensheathing cells (OECs), another type of cell believed to arise from the olfactory placode $[5,16,17]$, are also of $\mathrm{NC}$ lineage. We also show through the culture of olfactory mucosa-derived spheres the presence of $\mathrm{NC}$ progenitor cells, suggesting that NC-derived cells may in part be responsible for the remarkable capacity of the $\mathrm{OE}$ for neurogenesis and regeneration.

\section{Results}

\section{Neural crest-derived cells in the olfactory epithelium}

Transgenic mice harboring a Cre recombinase gene driven by promoters of either Wnt1 or P0 were crossed with the floxed CAG-EGFP reporter mice, generating the double transgenic mice Wnt1-Cre/Floxed-EGFP [18-20] and P0-Cre/Floxed-EGFP [21] in which cells of the NC lineage are indelibly tagged with EGFP. In both transgenic mice, $\mathrm{GFP}^{+}$cells were found in tissues known to contain $\mathrm{NC}$-derived cells such as the dorsal root ganglia, sympathetic nerve ganglia, enteric nervous system, and outflow tract of the heart, and also in the stroma of various tissues including bone marrow, cornea, and kidney, confirming the effective and specific marking of the NC lineage as demonstrated in our previous studies [22-25].

The classic behavior of NC cells is to delaminate from the neural tube early in embryogenesis and directly migrate to the target tissue, where they immediately begin to differentiate into the target-appropriate cell types. We therefore examined Wnt1-Cre/Floxed-EGFP and P0-Cre/Floxed-EGFP embryos to observe the migration of NC cells into the OE. At E10.5, the olfactory placode begins to invaginate in a process that leads to the formation of the olfactory pit. In both transgenic mice at E10.5, the developing OE at this stage is mostly negative for GFP while the underlying fibronectin ${ }^{+}$ mesenchyme contains numerous $\mathrm{GFP}^{+}$cells, supporting the fact that the $\mathrm{OE}$ mainly develops from the olfactory placode and that $\mathrm{NC}$ cells are present in the frontonasal mesenchyme at this stage. From E11.5, the presence of $\mathrm{GFP}^{+}$cells in the OE is observed in both Wnt1-Cre/ Floxed-EGFP (Figures 1a and 1b) and P0-Cre/FloxedEGFP mice (Figures $1 \mathrm{c}$ and 1d), suggesting that NC-derived cells give rise to cells of the OE. $\mathrm{GFP}^{+}$cells 

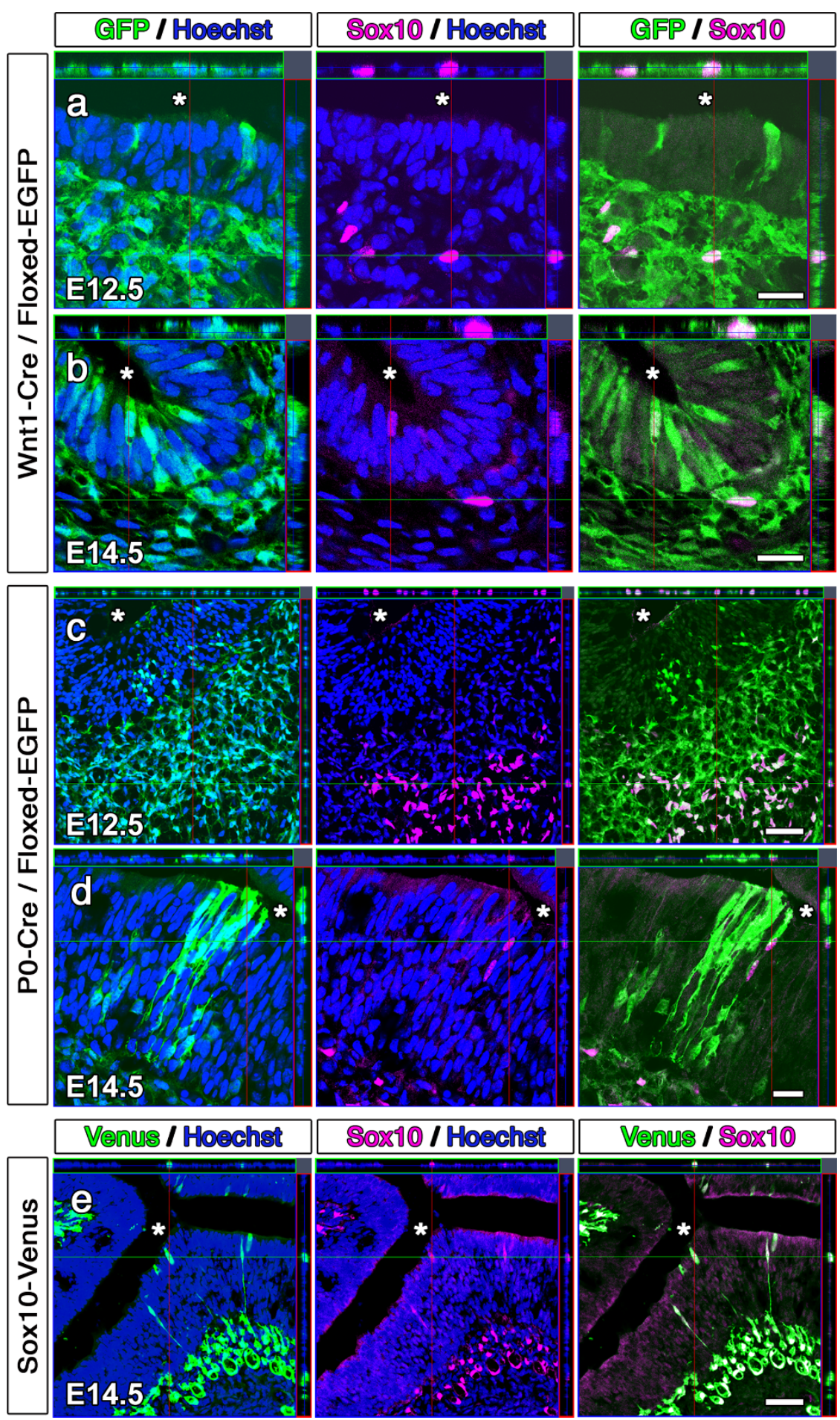

Figure 1 Neural crest-derived cells in the embryonic olfactory epithelium. a-d, Confocal images of direct GFP fluorescence and anti-Sox10 immunostaining in the olfactory epithelium of E12.5 (a) and E14.5 (b) Wnt1-Cre/Floxed-EGFP mice and E12.5 (c) and E14.5 (d) P0-Cre/FloxedEGFP mice reveal the presence of neural crest-derived cells in the olfactory epithelium. $\mathbf{e}$, Confocal images of direct Venus fluorescence and antiSox10 immunostaining in the olfactory epithelium of E14.5 Sox10-Venus mice confirm the presence of neural crest-derived cells in the olfactory epithelium. Asterisks indicate the nasal cavity. Scale bars: (a, b, d) $20 \mu \mathrm{m}$, (c, e) $50 \mu \mathrm{m}$. 
are found sporadically in the $\mathrm{OE}$ at first, and gradually increase in the embryonic epithelium until the late embryonic stage in both transgenic mice. These $\mathrm{GFP}^{+}$ cells are not found uniformly throughout the OE, but rather in clusters of $\mathrm{GFP}^{+}$cells that span the epithelium.

In order to rule out ectopic expression of Wnt1 or P0 in the embryonic stage, we performed anti-Wnt1 and anti-P0 immunostaining in E10.5 and E14.5 mouse embryos. Although limited expression of both Wnt1 and P0 was observed in the mesenchyme, their expression was not observed in the developing epithelium, confirming that the GFP expression observed in the OE of Wnt1-Cre/Floxed-EGFP and P0-Cre/Floxed-EGFP mice is due to Cre-mediated recombination during ontogeny of $\mathrm{NC}$ cells rather than ectopic Cre expression in the epithelium. We also verified Cre-mediated recombination in $\mathrm{GFP}^{+}$cells by conducting PCR of $\mathrm{GFP}^{+}$cells collected from the olfactory mucosa through flow cytometry (Additional File 1) and confirmed the absence of $\mathrm{GFP}^{+}$cells in the $\mathrm{OE}$ of the reporter gene single transgenic mouse.

Since the transcription factor Sox10 is expressed in migrating $\mathrm{NC}$ cells and is essential for the development and differentiation of various $\mathrm{NC}$-derived cell types, Sox10 immuno-reactivity is regarded as a classical NC marker. We performed immunohistochemistry for Sox10 and confirmed the expression of Sox10 in the nuclei of $\mathrm{GFP}^{+}$cells in the OE of E14.5 Wnt1-Cre/ Floxed-EGFP (Figure 1b) and P0-Cre/Floxed-EGFP (Figure 1d) embryos. However, not all $\mathrm{GFP}^{+}$cells had Sox $10^{+}$nuclei, and Sox10 immuno-reactivity was not observed in the OE until E13.5, suggesting that the $\mathrm{GFP}^{+}$cells of the transgenic mice and Sox $10^{+}$cells may be partially overlapping but different subpopulations of NC-derived cells.

In order to further elucidate the movement of Sox $10^{+}$ cells into the $\mathrm{OE}$ and to verify the presence of $\mathrm{NC}$ derived cells in the $\mathrm{OE}$, we examined the embryonic $\mathrm{OE}$ in another transgenic mouse line, the Sox10-Venus BAC transgenic mouse (Sox10-Venus). In Sox10-Venus mice, Venus fluorescence faithfully mirrors endogenous Sox10 expression, with transient fluorescence observed in developing NC-derived tissues such as the dorsal root ganglia, melanoblasts, and Schwann cells [26]. The intensity of Venus fluorescence makes it possible to identify Sox10 expression at the single cell level. At E11.5, in which $\mathrm{GFP}^{+}$cells begin to appear in the OE of Wnt1-Cre/Floxed-EGFP and P0-Cre/Floxed-EGFP mice, Venus $^{+}$cells are observed in the cranial mesenchyme but not in the OE of Sox10-Venus mice. As development progresses these Venus $^{+}$cells migrate in the mesenchyme in a caudal to rostral direction and arrive in the nasal mesenchyme by E12.5. Venus ${ }^{+}$cells are found in the OE of Sox10-Venus mice by E13.5, and
anti-Sox10 immunohistochemistry verifies the expression of the Sox10 protein in these Venus ${ }^{+} \mathrm{OE}$ cells (Figure 1e). The migration of Venus ${ }^{+}$cells from the lamina propria into the OE of Sox10-Venus mice verifies the results obtained by anti-Sox10 immnohistochemistry performed on Wnt1-Cre/Floxed-EGFP and P0-Cre/Floxed-EGFP mice, in which Sox $10^{+}$cells are observed only in the lamina propria at E12.5, and appear in the OE by E13.5. All Sox $10^{+}$cells in Wnt1-Cre/ Floxed-EGFP and P0-Cre/Floxed-EGFP mice were also positive for GFP, suggesting that Sox $10^{+} \mathrm{NC}$-derived cells are a subset of the $\mathrm{GFP}^{+} \mathrm{NC}$-derived cells identified by GFP expression in Wnt1-Cre/Floxed-EGFP and P0-Cre/Floxed-EGFP mice.

\section{Cell tracing studies in chick embryos}

In order to confirm our observations in transgenic mice, we conducted cell tracing studies of NC cells in chick embryos to verify their migration into the OE. The chick has been used as a model system to study vertebrate development mainly due to the ease of manipulating the embryo, and the research of NC cells has been extensively conducted with chick-quail chimeras $[27,28]$. However, surgical ablation or transplantation of the neural fold or neural tube before onset of NC cell migration would be technically demanding and often incurs collateral damage to adjacent tissue, requiring careful consideration when interpreting the results. Furthermore, since NC cells are required for olfactory placode development $[7,8]$, we elected to perform labelling and tracing of the $\mathrm{NC}$ cells and not ablation or transplantation procedures that may lead to the deformation or absence of the olfactory organ. We introduced a reporter gene into the embryo by in ovo electroporation, using the Tol2 transposon system that allows for continual expression of the reporter gene until late developmental stages.

A plasmid DNA containing the transposase cDNA under the control of a ubiquitous promoter (CAGGS) and a transposon-donor plasmid DNA containing a Tol2 construct with the CAG promoter and the gene encoding GFP [29] were introduced into the anterior neural fold of Hamburger and Hamilton stage 8 chick embryos by electroporation (Figure 2a) [15,30]. Initial GFP fluorescence was observed by post-electroporation (PE) 3 - 4 hours, and the migration of the labelled $\mathrm{GFP}^{+}$cells from the neural tube was observed by PE 6 hours. The anterior migration of the $\mathrm{GFP}^{+}$cells was observed at PE 24 hours, and $\mathrm{GFP}^{+}$cells were observed in the frontonasal and periocular areas by PE 48 hours (Figure 2b). The time frame and migration pathway of the labelled cells strongly suggest the successful labelling of the NC cells. To confirm that the migrating cells are NC cells, embryos were processed for immunohistochemistry and stained 

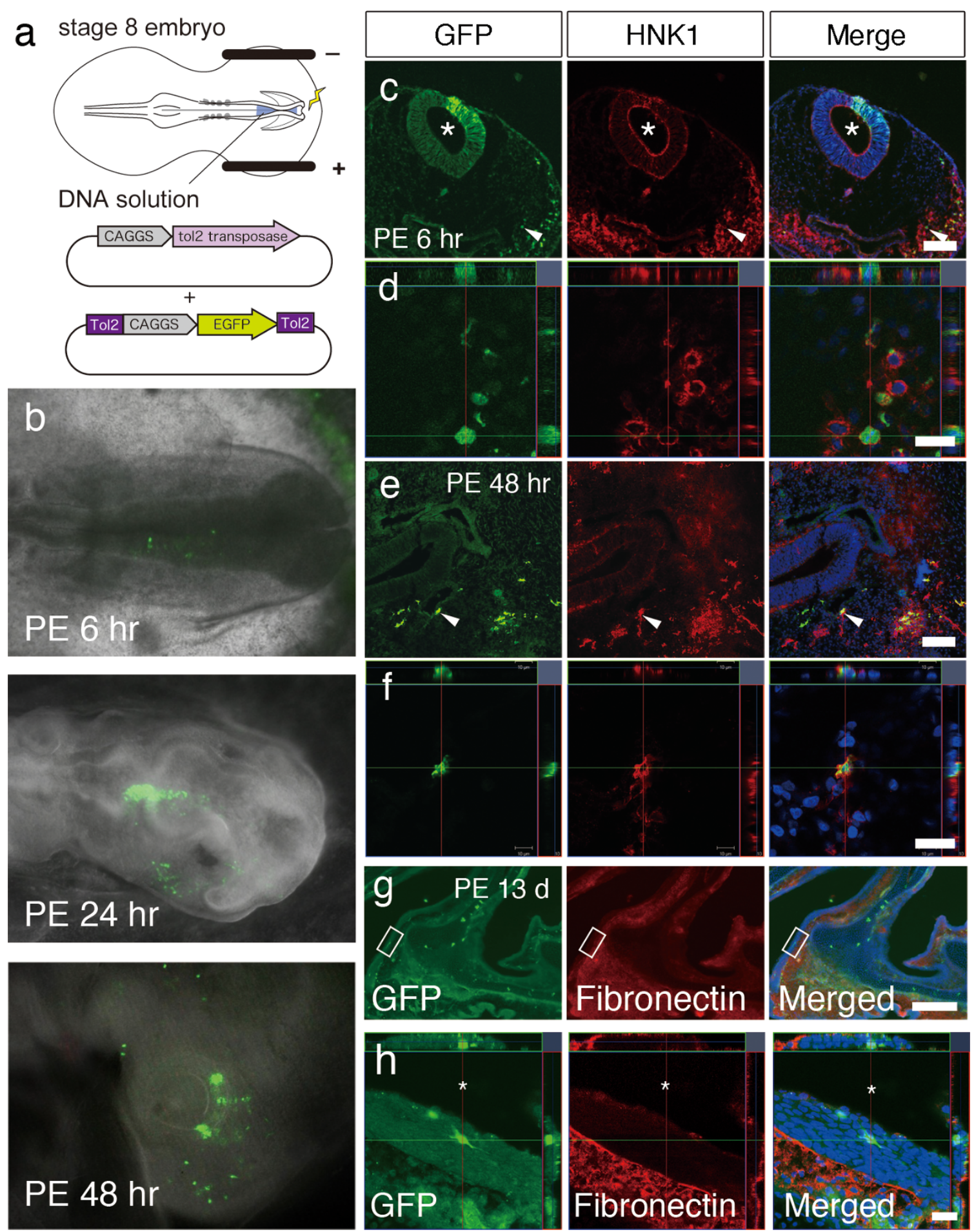

Figure 2 Cell tracing study of neural crest cells in chick embryos. a, Experimental schema for cell tracing of neural crest cells in the chicken embryo. Constructs were electroporated into the neural fold of stage 8 embryos at the midbrain and anterior hindbrain level before neural crest cells delaminate from the neural tube. $\mathbf{b}$, Stereoscopic images of GFP fluorescence observed in the in ovo chick embryo at 6, 24, and 48 hours after introduction of GFP by electroporation into the neural fold. c-f, Confocal images of direct GFP fluorescence and immunostaining of HNK1 in the chick embryos at 6 hours (c, $\mathbf{d})$ and 48 hours $(\mathbf{e}, \mathbf{f})$ after electroporation. The asterisks in $\mathbf{c}$ indicate the neural tube, while the arrowheads in $\mathbf{c}$ and $\mathbf{e}$ indicate the double positive cells magnified in $\mathbf{d}$ and $\mathbf{f}$, respectively. $\mathbf{g}, \mathbf{h}$; Confocal images of direct GFP fluorescence in the olfactory mucosa of chick embryos at 13 days after electroporation. The boxes in $\mathbf{g}$ indicate the area magnified in $\mathbf{h}$. Anti-fibronectin staining demarcates the mesenchyme of the olfactory mucosa and demonstrates the presence of a GFP ${ }^{+}$neural crest cell in the olfactory epithelium. The asterisks in $\mathbf{h}$ indicate the nasal cavity. Nuclei were counterstained with Hoechst. Scale bars: (c, e) $100 \mu \mathrm{m},(\mathbf{d}, \mathbf{f}, \mathbf{h}) 20 \mu \mathrm{m}$, and (g) $200 \mu \mathrm{m}$. 
with the HNK-1 antibody, which recognizes a carbohydrate moiety that is present on the surface of migrating avian NC cells and is regarded to be a marker for avian NC cells [31]. At PE 6 hours, the area of the neural tube in which the DNA was introduced is $\mathrm{GFP}^{+}$, and $\mathrm{GFP}^{+}$ cells are observed delaminating in streams ventrally and laterally from the dorsal tube between the neural tube and the overlying ectoderm in a course that is typical of $\mathrm{NC}$ cells (Figure 2c). At PE 48 hours, $\mathrm{GFP}^{+}$cells are observed in the frontonasal mesenchyme (Figure 2e). Immunohistochemistry for $\mathrm{HNK}-1$ confirmed that the $\mathrm{GFP}^{+}$cells were also positive for HNK-1 in both PE 6 and 48 hour-sections (Figures $2 \mathrm{~d}$ and $2 \mathrm{f}$ ), demonstrating the successful labelling of the NC cells. The embryos were then allowed to sufficiently develop in ovo, and were sectioned for histology. At PE 13 days, a limited number of $\mathrm{GFP}^{+}$cells were found in the $\mathrm{OE}$, confirming that NC cells also give rise to cells in the embryonic chick OE (Figures 2g and 2h).

\section{Identity of neural crest-derived cells in the olfactory epithelium}

Since the observations from the transgenic mice and chick cell tracing studies revealed the presence of NCderived cells in the OE, we performed immunohistochemistry to examine which cell types of the OE are produced by the NC. In this experiment, we performed the identification of specific epithelial cell types in postnatal animals because the identification of epithelial cells based upon their location within the OE becomes more apparent, and also to allow for complete differentiation and antigenic maturation since markers for horizonatal basal cells (HBCs) are not observed in the embryonic period.

The postnatal $\mathrm{OE}$ is a pseudostratified columnar epithelium overlying the lamina propria and is composed of five basic cell types that can be distinguished on morphological, biochemical, and antigenic characteristics. Deep in the epithelium are HBCs and globose basal cells (GBCs) that are regarded as the transit amplifying progenitors of the OE [32,33]. Aligned on the surface are sustentacular (SUS) cells with thin cytoplasmic projections that terminate at the basal lamina. Olfactory receptor neurons (ORNs) are situated in an intermediate zone between these basal and apical layers, and make up the bulk of the epithelium. The remaining cell type is the Bowman's gland/duct complex that extends from the glands in the lamina propria to the ducts within the epithelium, which carry the secretions to the apical epithelial surface.

The $\mathrm{GFP}^{+} \mathrm{NC}$-derived cells in the postnatal OE of Wnt1-Cre/Floxed-EGFP and P0-Cre/Floxed-EGFP mice had morphologies compatible with cells normally constituting the epithelium, and we conducted immunohistochemical staining for specific markers of $\mathrm{OE}$ cells to verify their identities. $\mathrm{GFP}^{+}$cells lining the basement membrane of the OE were mostly ICAM1 ${ }^{+}$ HBCs (Figures $3 \mathrm{a}$ and $3 \mathrm{~d}$ ). Among the $\mathrm{GFP}^{+}$cells in the basal layer, a limited number of $\mathrm{Mash}^{+} \mathrm{GBCs}$ (Figure 3c) were identified. The $\mathrm{GFP}^{+}$cells spanning the $\mathrm{OE}$ were CK18 ${ }^{+}$SUS cells and some Bowman's gland/ducts (Figures $3 \mathrm{~b}$ and $3 \mathrm{e}$ ). In both strains however, $\mathrm{GFP}^{+}$ ORNs were not observed.

While the $\mathrm{GFP}^{+}$cells in the embryonic Wnt1-Cre/ Floxed-EGFP and P0-Cre/Floxed-EGFP OE were distributed in clusters, this distribution was more apparent in postnatal animals. Clusters of $\mathrm{GFP}^{+}$cells including both basal and apical cells were sporadically observed, along with large areas of the $\mathrm{OE}$ with no apparent $\mathrm{GFP}^{+}$cells. $\mathrm{GFP}^{+} \mathrm{HBCs}$ and GBCs were observed along with SUS cells and Bowman's gland/ducts, suggesting that these transient progenitors gave rise to the SUS cells situated directly apical to their position (Figure 3).

Considering the accepted proliferation and differentiation process of the OE in which epithelial cells are replenished by transit amplifying progenitors in the basal aspect of the epithelium, we could not explain the absence of $\mathrm{GFP}^{+}$ORNs. It is possible that $\mathrm{NC}$-derived cells were responsible for the replenishment/regeneration of non-neuronal cells, or that the silencing of the CAG promoter occurred in the olfactory neuronal-lineage cells. We therefore created another double transgenic mouse line by crossing P0-Cre mice with mice carrying the ROSA26 conditional reporter transgene, thereby generating mice in which $\mathrm{NC}$-derived cells are labeled with $\beta$-galactosidase (P0-Cre/Floxed-LacZ). Observation of the OE in P0-Cre/Floxed-LacZ mice revealed $\beta$-galactosidase expression in a subset of ORNs (Figure 3f) and also in HBCs (Figure 3g), SUS cells, and Bowman's gland/ducts. These results demonstrated that NC-derived cells have the capability to differentiate into all cell types of the OE.

\section{Olfactory ensheathing cells are derived from the neural crest}

The primary olfactory pathway consists of ORNs in the OE whose axons project through the cribriform plate to synapse with cells in the olfactory bulb in the central nervous system (CNS). Along the course of the nonmyelinated olfactory nerves, they are accompanied by OECs that ensheath and compartmentalize the small olfactory axons into fascicles [34]. OECs have a unique property that allows regenerating olfactory nerves to cross the peripheral/central nerve threshold and have thus been attracting interest as a potential source for transplantation to treat CNS ailments. While OECs were believed to be derived solely from the olfactory placode based on past observational studies $[5,16,17]$, OECs display several 

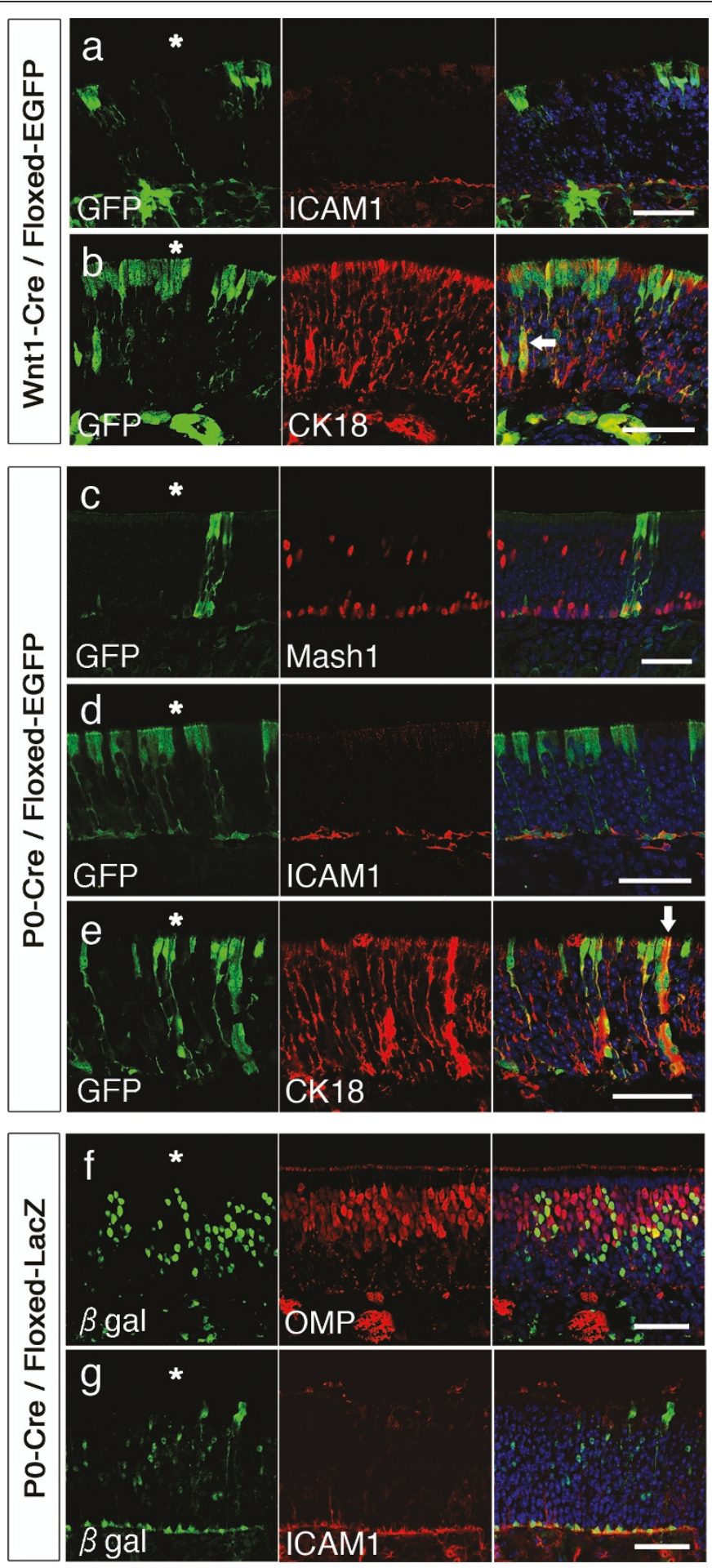

Figure 3 Identification of neural crest-derived cells in the olfactory epithelium. Confocal images of the olfactory epithelium in Wnt1-Cre/ Floxed-EGFP (a, b) and P0-Cre/Floxed-EGFP (c-e) mice stained for the indicated markers reveal the presence of neural $\mathrm{Crest}^{-}$derived ICAM1 ${ }^{+}$ $\mathrm{HBCs}$, Mash $1^{+} \mathrm{GBCS}$, and CK18 $8^{+}$SUS cells in the olfactory epithelium. All images of GFP are direct fluorescence observed in postnatal 4-week mice, except for the Mash1 staining in $\mathbf{c}$ that was observed in postnatal 2-day mice and required anti-GFP immunostaining after antigen retrieval procedures. OMP ${ }^{+}$ORNs $(\mathbf{f})$ and ICAM1 ${ }^{+}$HBCs $(\mathbf{g})$ were observed in 4 week-old PO-Cre/Floxed-LacZ $(\mathbf{f}, \mathbf{g})$ mice. Nuclei were counterstained with Hoechst. Arrows in $\mathbf{b}$ and $\mathbf{e}$ indicate $\mathrm{CK} 18^{+}$ducts of Bowman's glands and asterisks indicate the nasal cavity. Scale bars: $50 \mu \mathrm{m}$. 
characteristics that suggest a $\mathrm{NC}$ origin. OECs are peripheral glia and share multiple characteristics with Schwann cells [17]. All other peripheral glia, including Schwann cells, satellite cells, enteric glia [27], and acoustic glia [35] develop from the NC. Furthermore, OECs express p75, a $\mathrm{NC}$ marker expressed in all other peripheral glia.

To verify that OECs are derived from the NC, the olfactory mucosa of Wnt1-Cre/Floxed-EGFP mice was examined for GFP expression. P0-Cre/Floxed-EGFP mice were not used to study OECs since adult OECs have been shown to express the P0 protein in situ [13], but we have also confirmed that OECs are $\mathrm{GFP}^{+}$in P0-Cre/Floxed-EGFP mice (data not shown). In Wnt1Cre/Floxed-EGFP mice, $\mathrm{GFP}^{+}$cells were found in areas known to be populated by OECs: surrounding axons in the olfactory nerve fascicles of the lamina propria (Figure 4b), accompanying olfactory nerve axons through the cribriform plate (white arrows in Figures 4a and $4 \mathrm{c}$ ), and in the outer layer of the olfactory bulb (white arrowheads in Figures $4 \mathrm{a}$ and $4 \mathrm{c}$ ). These $\mathrm{GFP}^{+}$ cells were positive for OEC markers p75 (Figure 4d), GFAP (Figure 4e), and S100 $\beta$ (Figure 4f), indicating that these NC-derived cells are OECs. To verify GFP expression in OECs, the olfactory mucosa was dissected from Wnt1-Cre/Floxed-EGFP mice and primary OEC cells were cultured. Although we cannot exclude the possibility of OEC development from the placode or other sources, OECs identified by expression of OEC markers p75, GFAP, and S100 $\beta$ were $\mathrm{GFP}^{+}$(Figure 4g), demonstrating that at least a subset of OECs are derived from the NC. Furthermore, OECs in the olfactory system of embryonic Sox10-Venus mice were positive for Venus, verifying the expression of Sox10 in embryonic OECs (Figures $4 \mathrm{~h}$ and $4 \mathrm{i}$ ).

Recently, the NC origin of OECs was demonstrated by fate-mapping techniques in chick embryos and examination of Wnt1-Cre/ROSA-LacZ or -YFP mice [36]. Our results confirm their findings and also demonstrate that OECs cultured from Wnt1-Cre/Floxed-EGFP mice are positive for GFP. The presence of $\mathrm{GFP}^{+}$cells in the $\mathrm{OE}$ were attributed to the presence of Bowman's glands, but our results demonstrate that GFP expression is observed in the other cells constituting the OE.

\section{Neural crest progenitor cells of the olfactory mucosa}

The NC has recently been receiving great interest, with reports of sphere-forming NC stem/progenitor cells being isolated and cultured from numerous tissues containing NC-derived cells such as the skin [37], whisker follicles [38], heart [23], adipose tissue [39], cornea [22], and bone marrow [24]. Since our results demonstrated the presence of $\mathrm{NC}$-derived cells in the $\mathrm{OE}$, we examined spheres cultured from the olfactory mucosa for $\mathrm{NC}$ progenitor cells, suspecting that the multipotency of neurospheres previously described to be cultured from the $\mathrm{OE}[40,41]$ may be due to the presence of $\mathrm{NC}$ progenitor cells. By culturing dissociated cells of the olfactory mucosa in medium containing epidermal growth factor (EGF) and fibroblast growth factor-2 (FGF-2), large populations of floating spheres were obtained by 3 to 4 weeks. Spheres were cultured from both the $\mathrm{OE}$ and lamina propria when an attempt was made to divide and culture these segments separately. However, since a complete separation of the OE from the lamina propria is technically impossible, we decided to dissociate and culture the whole olfactory mucosa. To determine the characteristics of these sphere-forming cells, we performed clonal density sphere cultures in medium containing 1\% methylcellulose. This method was demonstrated to be effective in preventing sphere fusion [22,24], with over $90 \%$ of the generated spheres being clonal (Additional File 2). Spheres cultured from the olfactory mucosa of both Wnt1-Cre/Floxed-EGFP and P0-Cre/Floxed-EGFP mice were $\mathrm{GFP}^{+}$, revealing that the sphere-forming cells are derived from the NC (Figures $5 \mathrm{a}$ and $5 \mathrm{~b}$ ), and immunohistochemistry of these spheres revealed Nestin expression. Passage of these spheres generated secondary and tertiary spheres, demonstrating self-renewal of the cells constituting the spheres. To examine the RNA profile of these spheres for expression of NC lineage markers, RT-PCR analysis of the following samples cultured/obtained from P0Cre/Floxed-EGFP mice was performed: spheres cultured from the olfactory mucosa (OM sphere), $\mathrm{GFP}^{+}$primary olfactory mucosa cells sorted by flow-cytometry (OM primary), primary neurospheres cultured from the striatum of neonates (CNS sphere), and tissue collected from the frontonasal area (frontonasal tissue) which was included as a positive control for NC cells (Figure 5c). All of the examined NC markers were detected in olfactory mucosa spheres, OM primary cells, and frontonasal tissue cells. Olfactory mucosa spheres did not express $\mathrm{P} 0$ or $\mathrm{p} 75$, but $\mathrm{P} 0$-expression was detected in primary olfactory mucosa cells due to the presence of OECs.

To examine the multipotency of the cells contained in olfactory mucosa spheres, we performed differentiation assays of clonal spheres and compared the results with that of clonal spheres cultured from the dorsal root ganglion, a tissue in which $\mathrm{NC}$ stem/progenitor cells are known to exist $[24,42]$. Clonal spheres were individually collected, plated in differentiation medium for 10 days, and stained to identify the three types of cells reported to be generated by NC stem/progenitor cells: $\beta$ III-tubulin ${ }^{+}$ neurons (N), GFAP ${ }^{+}$glial cells $(\mathrm{G})$, and $\mathrm{SMA}^{+}$myofibroblasts $(\mathrm{M})$ [43]. Olfactory mucosa spheres demonstrated a trilineage (NGM) differentiation potential $(27.1 \pm 4.7 \%)$ (Figures $5 \mathrm{~d}$ and $5 \mathrm{e}$ ), suggesting the presence of $\mathrm{NC}$ progenitor cells. This proportion was lower than that of dorsal 


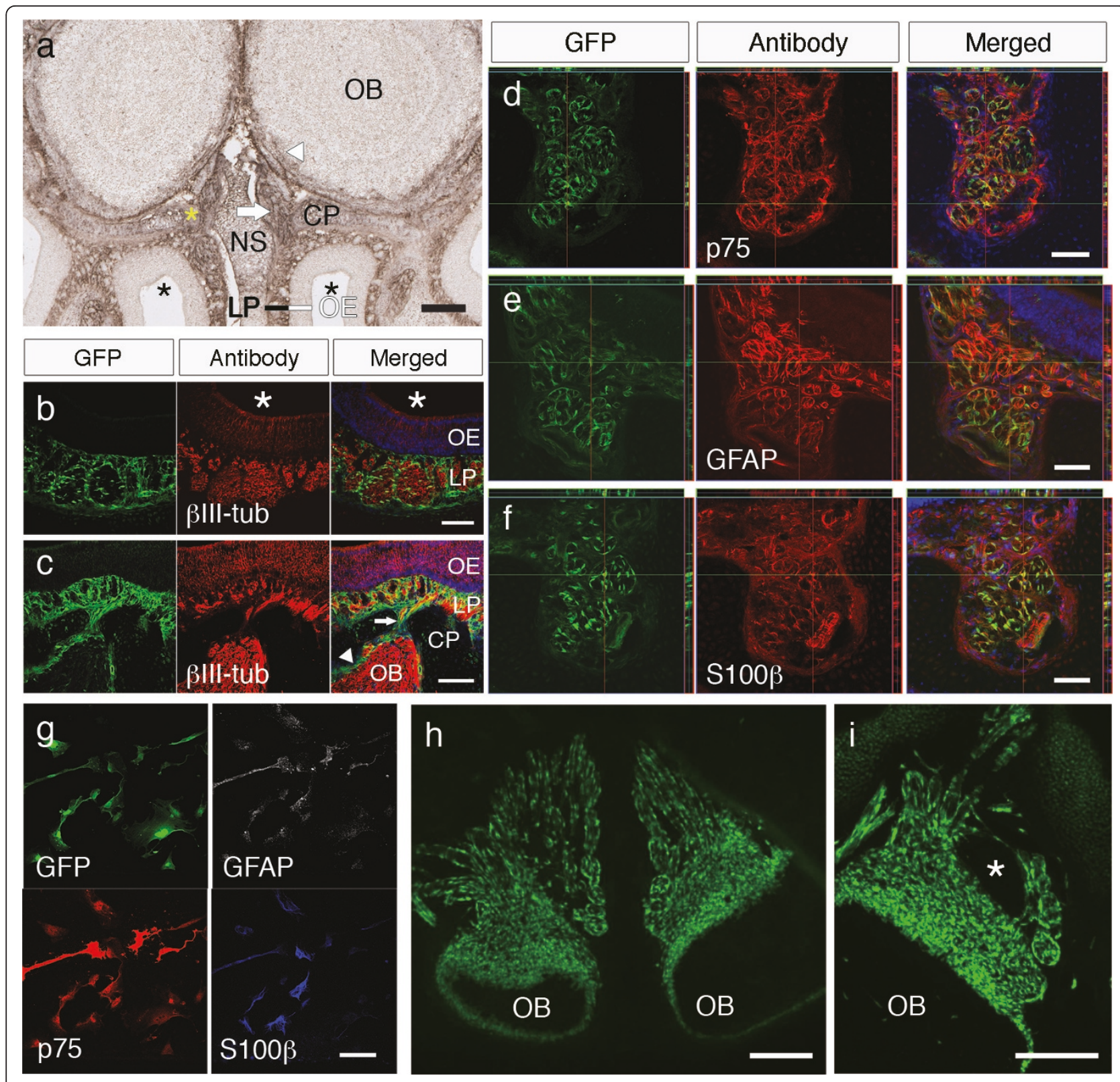

Figure 4 GFP expression in OECs from Wnt1-Cre/Floxed-EGFP mice. a, Anti-GFP DAB-nickel-staining of the olfactory system reveals GFP expression in areas populated by OECs. The white arrow indicates the olfactory nerve traversing the cribriform plate from the olfactory mucosa to the olfactory bulb. The white arrowhead indicates the outer layer of the olfactory bulb with GFP ${ }^{+}$cells. Note that the skeletal system and the meninges, which are derived from the neural crest, are also positive for GFP. The yellow asterisk indicates the area observed in $\mathbf{d}$-f, which corresponds to the groove in the cribriform plate where the olfactory nerves pass before crossing the cribriform plate and the black asterisks indicate the nasal cavity. $\mathbf{b}-\mathbf{c}$, Confocal images of the olfactory system showing direct GFP fluorescence and immunostaining for $\beta$ III-tubulin. The arrow indicates the olfactory nerve passing through the cribriform plate and the arrowhead indicates the outer layer of the olfactory bulb with GFP $^{+}$cells. $\mathbf{d}$-f, Cross-section images of the olfactory nerve before it passes through the cribriform plate, displayed as Z-stack confocal images with corresponding $x$ - and $y$-axes, showing GFP fluorescence and immunostaining for OEC markers p75 (d), GFAP (e), and S100ß (f). All images are oriented with the olfactory mucosa above and the olfactory bulb below the shown area. $\mathbf{g}$. Primary OEC cells cultured from the olfactory mucosa and verified by multiple OEC markers were positive for GFP, verifying their neural crest origin. $\mathbf{h}-\mathbf{i}$, Venus fluorescence in Sox10-Venus mice verifies the expression of Sox10, a neural crest marker, in OECs at E14.5 (h) and E15.5 (i) The asterisk indicates the nasal cavity. OE: olfactory

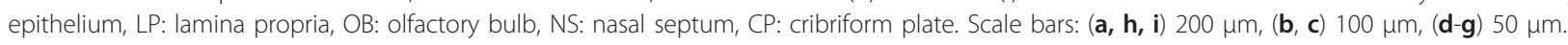




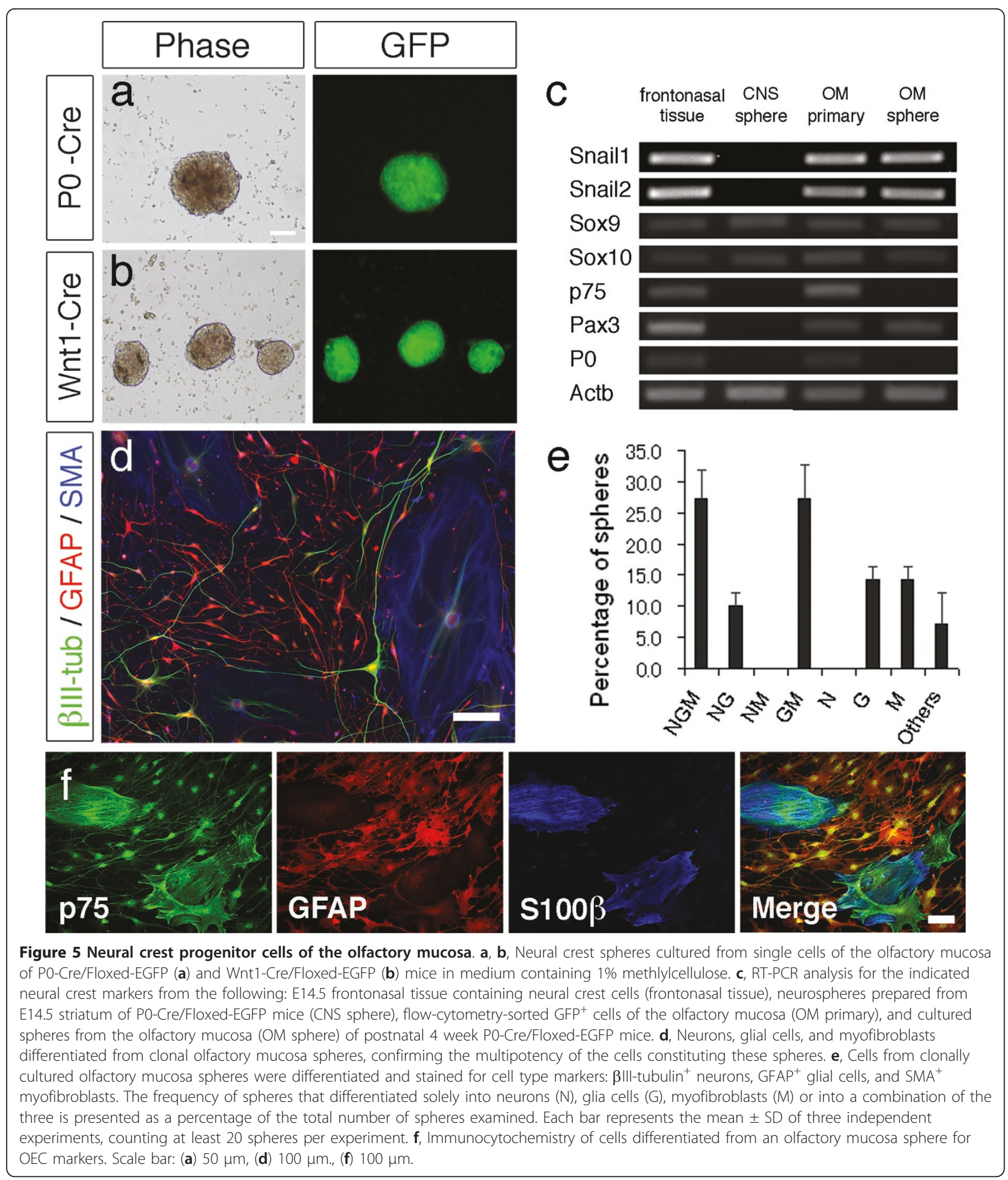

root ganglion spheres $(74.6 \pm 1.0 \%)$ which generally demonstrate a neuron-dominant differentiation pattern [24]. On the other hand, olfactory mucosa spheres demonstrated a glia-dominant differentiation pattern (GM 27.1 \pm $5.5 \%$; NG $10.0 \pm 2.2 \%$; G $14.3 \pm 2.1 \%$; M $14.3 \pm 2.1 \%$; no NM or N). Cell-intrinsic differences have been shown to determine the differentiation characteristics of NC stem/progenitor cells [44], and our results indicate that the olfactory mucosa contains NC stem progenitors that are predisposed to a glial lineage. Furthermore, 
immunocytochemistry of differentiated cells revealed the presence of cells that were positive for OEC markers (Figure $5 \mathrm{f}$ ), suggesting that the $\mathrm{NC}$ progenitor cells of the olfactory mucosa spheres are able to produce OECs. Most cells were found to be $\mathrm{p} 75^{+}$, possibly reflecting their $\mathrm{NC}$ origin, since p 75 has consistently been observed to mark NC stem cells in the gut [45-47] and other tissues. Cells double positive for p75 and $S 100 \beta$ generally had a flat morphology while p75 and GFAP double-positive cells had spindly bipolar, tripolar, or stellate morphologies.

\section{Discussion}

The olfactory placode has been described as one of the most versatile placodes, being unique in its capacity to give rise to glial cells and stem cells capable of generating various differentiated cell types of the OE throughout life. However our findings suggest that the unique properties that have been attributed solely to the olfactory placode may in part be properties endowed by NC-derived cells. In this study, we demonstrate the presence of postmigratory $\mathrm{NC}$ progenitor cells within the olfactory mucosa and show that OECs are derived from the NC. Furthermore, even though the majority of cells in the $\mathrm{OE}$ are derived from the olfactory placode, we demonstrate the capacity of NC-derived cells to give rise to all cell types of the OE.

The OE, with its capacity for continual neurogenesis in adults, has long been a hotspot for the study of neuroscience. However, identifying different progenitors in the embryonic or adult OE has been historically challenging due to the difficulty in distinguishing distinct embryonic and adult olfactory epithelial progenitors, expanding them in vitro, and demonstrating their developmental potential in vivo. With the development of sophisticated transgenic mouse technologies, it has become possible to demonstrate the relationship between progenitors and its descendants and to temporally map the progeny derived from a progenitor in fine developmental time windows. By utilizing transgenic mice that express Cre recombinase behind one of two promoters (derived from the Wnt1 or P0 gene) known to be active in migrating $\mathrm{NC}$ cells, we demonstrated the presence of NC-derived cells in the embryonic and postnatal OE.

Clusters of $\mathrm{GFP}^{+}$cells spanning the epithelium were observed from E10.5, and generally gradually increased in number during the embryonic period. In the mouse $\mathrm{OE}$, neurogenesis during embryonic establishment (E10 - E18.5), postnatal expansion (P0 - P30), and adult maintenance (P30-) proceed with distinct, spatiotemporal patterns and different cellular and extracellular environments. During embryonic OE development, there is a dramatic expansion of epithelial cells that is brought about by proliferating cells that are equally distributed between the apical and basal OE during early embryonic stages, but become largely located at the basal area by late embryonic stages [48]. The observed increase in $\mathrm{GFP}^{+}$cells during the embryonic period suggests that $\mathrm{NC}$-derived cells may support cell expansion during the early embryonic period.

We found that a subset of cells in the embryonic olfactory mucosa expressed Sox10, which has been shown to be required for the survival and maintenance of multipotent NC cells. Sox10 is also required for specification of NC cells to the glial lineage, since peripheral glia is absent in Sox10-deficient mice $[49,50]$. Further studies are required to elucidate the characteristics of the Sox10-expressing cells in the olfactory system, but these cells may be multipotent NC progenitor cells or mature olfactory cells that have differentiated into OECs or SUS cells, because Sox10 has been shown to be expressed in Schwann cells after specification to the glial lineage [51].

The presence of scattered clusters of $\mathrm{GFP}^{+}$cells in the postnatal mice $\mathrm{OE}$ with morphologic and antigenic properties identical to olfactory placode-derived epithelial cells demonstrate that $\mathrm{NC}$-derived cells retain the potential to give rise to epithelial cells in adults. Unlike the $\mathrm{NC}$-derived cells in the embryonic $\mathrm{OE}$ that seem to participate in the expansion of $\mathrm{OE}$ cells, NC-derived cells in the postnatal OE were often observed as clusters of $\mathrm{GFP}^{+}$cells. The clusters of $\mathrm{GFP}^{+}$cells were often comprised of HBCs, SUS cells, and Bowman's gland/ duct cells, and the presence of $\mathrm{GFP}^{+} \mathrm{GBCs}$ along with $\beta$-galactosidase ${ }^{+}$ORNs in P0-Cre/Floxed-LacZ mice were also observed. HBCs are relatively quiescent, and do not take part in the normal maintenance of the $\mathrm{OE}$ or the replenishment of the $\mathrm{OE}$ after olfactory bulbectomy, in which GBCs lead the repopulation effort. However in extensive epithelial lesions following methlyl bromide exposure, HBCs demonstrate a multilineage potential that regenerates all cell types of the epithelium [33]. Since $\mathrm{GFP}^{+} \mathrm{HBCs}$ were frequently observed in the sporadic $\mathrm{GFP}^{+}$cell patches of the postnatal Wnt1-Cre/ Floxed-EGFP and P0-Cre/Floxed-EGFP mice OE, NCderived cells may give rise to $\mathrm{HBCs}$ that later generate other cells of the epithelium. This hypothesis may be examined through methlyl bromide lesion experiments with Wnt1-Cre/Floxed-EGFP and P0-Cre/Floxed-EGFP mice. The fact that $\mathrm{HBCs}$ in culture have demonstrated the capacity to generate OECs along with neurons and other non-neural cells verifies another characteristic of HBCs that may be related to the NC [52].

The multipotent developmental capacity of NC cells to differentiate into both neuronal and mesenchymal derivatives [22,53-55] has resulted in the NC being considered a fourth germ layer. The multipotency and self-renewal of NC cells from various embryonic sources 
in vitro demonstrated the presence of NC stem/progenitor cells. With the discovery of multipotent NC stem/ progenitor cells not only in late gestation embryonic tissues but also in adults, the possibility of therapeutic applications has initiated intense studies to identify and characterize NC stem/progenitor cells in multiple $\mathrm{NC}$-derived adult tissues. Here, we demonstrate the capacity of NC-derived cells of the olfactory mucosa to generate spheres in vitro, a characteristic of proliferative NC-derived cells. Furthermore, when placed on serumcontaining differentiation medium, these spheres exhibited a trilineage differentiation potential by giving rise to neurons, glial cells, and myofibroblasts, thus indicating the presence of NC progenitor cells in the olfactory mucosa. The frequency of olfactory mucosa spheres with a trilineage potential was $27.1 \%$, which is considerably lower than that of $\mathrm{NC}$ progenitor cells derived from the dorsal root ganglion (74.6\%). A series of our recent reports on $\mathrm{NC}$ stem/progenitor cells has shown that their self-renewal capacity is reflective of their differentiation capacity [24], providing a possible explanation for the limited expansion capacity of olfactory mucosa-derived NC progenitor cells compared to dorsal root ganglion-derived NC progenitor cells. The differentiation characteristic of olfactory mucosa-derived NC progenitor cells demonstrated a glia-dominant differentiation pattern, confirming the in vivo data from the transgenic mice demonstrating the higher tendency of NC-derived cells to give rise to OECs and SUS cells. Although we have not examined the relationship between the olfactory mucosa-derived $\mathrm{NC}$ progenitor cells that we isolated and the progenitors of the $\mathrm{OE}$, our study suggests the possibility that cells derived from the $\mathrm{NC}$ may be involved in the remarkable regenerative capacity of the OE.

The isolation of NC-derived progenitor cells from the olfactory mucosa, with an established method for amplification as spheres and the ability to differentiate into OECs, opens the door to possible clinical applications. OECs, with the unique ability to guide axons into the CNS, have attracted the attention of researchers studying therapy strategies for neurotrauma, and cultured OECs have been shown to be beneficial for the treatment of peripheral and CNS ailments [56,57]. NCderived stem cells identified in numerous tissues have rapidly asserted its presence as a potential source for transplantation. Unlike embryonic stem cells that are hindered by ethical issues, NC-derived stem cells allow for autologous transplantation, and several NC-derived stem cells have been demonstrated to have a beneficial effect after transplantation into peripheral and CNS lesions. One of the well-documented and promising candidates is the $\mathrm{NC}$-derived stem cell found in the hair follicle. Nestin ${ }^{+}$stem cells isolated from the hair follicle can be cultured as spheres, and have demonstrated the ability to differentiate into neurons, glia, keratinocytes, smooth muscle cells, and melanocytes in vitro [58-61]. Subsequent studies showed that transplanted hair follicle stem cells could enhance the regrowth and functional rejoining of the severed sciatic and tibial nerves [62], as well as the severed spinal cord $[63,64]$, in immunocompetent mice. Although the capacity to generate OECs makes olfactory mucosa-derived NC progenitor cells an appealing transplantation candidate, the studies conducted with hair follicle stem cells clarifies the futures studies required to investigate the characteristics and therapeutic potential of this progenitor cell.

The cephalic sensory system develops through an intricate collaboration between sensory placodes and $\mathrm{NC}$ cells, and our results demonstrate that the role NC cells play in the development of the olfactory system is greater than previously reported. Our findings indicating a dual origin for cells of the OE inspire a resurgence of developmental research, and provide further evidence of the versatility and morphogenic capacity of NC cells.

\section{Methods \\ Mouse lines}

The P0-Cre mouse was obtained from Dr. K. Yamamura (Kumamoto University, Japan). Wnt1-Cre mouse and LacZ mice were purchased from The Jackson Laboratory. The CAG-CAT-EGFP mouse was obtained from Dr. J. Miyazaki (Osaka University, Japan). Wnt1-Cre and P0-Cre mice were crossed with CAG-CAT-EGFP transgenic mice to produce Wnt1-Cre/Floxed-EGFP and P0Cre/Floxed-EGFP mice, respectively. P0-Cre mice were crossed with LacZ mice to produce P0-Cre/Floxed-LacZ mice. All experimental procedures and protocols for animals conformed to the National Institutes of Health Guide for the Care and Use of Laboratory Animals and were approved by the Animal Care and Use Committees of Keio University.

\section{Immunohistochemistry}

Embryonic mice were anesthetized in ice, decapitated, and fixed overnight in $4 \%$ paraformaldehyde (PFA) in $0.1 \mathrm{M}$ phosphate buffered saline (PBS). After sequential treatment in a graded series of $10 \%$ and $30 \%$ sucrose in PBS at $4{ }^{\circ} \mathrm{C}$, the head was embedded in optimal cutting temperature (OCT) compound and sectioned on a cryostat at $15 \mu \mathrm{m}$. All mice over 2 weeks of age were deeply anesthetized, transcardially perfused with 4\% PFA in 0.1 M PBS and decapitated. After postfixation in 4\% PFA overnight at $4^{\circ} \mathrm{C}$, the skull was decalcified for 7 days in $0.5 \mathrm{M}$ EDTA (Decalcifying Solution B, Wako), and sequentially soaked in a graded series of $10 \%$ and $30 \%$ sucrose in PBS at $4^{\circ} \mathrm{C}$. The head was embedded in OCT compound and sectioned on a cryostat at $20 \mu \mathrm{m}$. 
Immunostaining was performed with the following primary antibodies: rabbit anti-fibronectin (Chemicon), mouse anti-Mash1 (R\&D Systems), mouse anti-cytokeratin 5/14 (Chemicon), mouse anti-cytokeratin 18 (Chemicon), goat anti-olfactory marker protein (OMP, Wako), mouse anti- $\beta$ III-tubulin ( $\mathrm{TuJ}-1, \mathrm{Babco})$, rabbit anti-glial fibrillary acidic protein (GFAP, Dako), mouse anti- $\alpha$ smooth muscle actin (SMA, Sigma-Aldrich), rabbit antip75 low affinity nerve growth factor-receptor (p75, Chemicon), mouse anti-S100 $\beta$ (Sigma-Aldrich), and rabbit anti- $\beta$ gal (Sigma). The competence of all immunohistochemisry procedures was confirmed with a negative control in which primary antibodies were omitted. Staining of Mash1 required an antigen retrieval procedure with $10 \mathrm{~min} 105^{\circ} \mathrm{C}$ autoclave in Target Retrieval Solution (TRS, Dako) followed by indirect immunoperoxidase amplication procedures using ABC-Elite (Vector Laboratories) and TSA (Perkin Elmer), in which case GFP was stained with anti-GFP polyclonal antibody (Chemicon). Staining of $\beta$ gal was also amplified with TSA (Perkin Elmer). Nuclei were counterstained with Hoechst 33342 (Molecular Probes). Images were obtained by fluorescence microscopy (Axioskop 2 Plus, Carl Zeiss) or confocal microscopy (LSM700, Carl Zeiss) and assembled using Adobe Photoshop.

\section{Cell tracing of neural crest cells in chick embryo}

Fertilized eggs were incubated at $38^{\circ} \mathrm{C}$ in a humid incubator to stage 8 according to Hamburger and Hamilton [65]. Embryos were exposed by making an opening at the sharp edge of the egg shell. DNA solution including $2 \mathrm{mg} / \mathrm{ml}$ pCAGGS-TP, $4 \mathrm{mg} / \mathrm{ml}$ pT2AL200R175CAGGFP [29], and 1\% fast green in TE buffer was injected to the anterior neural fold, which will give rise to the midbrain and anterior hindbrain. A pair of platinum electrodes CUY611P3-1 (Nepagene, Ichikawa, Japan) was placed on the vitelline membrane beside the embryos. Five square pulses (9 V, $25 \mathrm{msec}$ each) after a high-voltage pulse $(50 \mathrm{~V}, 0.05 \mathrm{msec})$ were charged by an electroporator CUY21EX (Bex, Tokyo, Japan). After electroporation, the opening was sealed with Scotch tape (Scotch 313), and the embryos were reincubated at $38^{\circ} \mathrm{C}$ until the desired stages. The embryos were dissected, fixed in $4 \%$ PFA overnight at $4{ }^{\circ} \mathrm{C}$, and sequentially soaked in a graded series of $10 \%$ and $30 \%$ sucrose in PBS at $4^{\circ} \mathrm{C}$. The embryo was embedded in OCT compound and sectioned on a cryostat at $20 \mu \mathrm{m}$.

\section{Olfactory mucosa cell preparation}

Animals were deeply anesthetized, killed by cervical dislocation and decapitated. The olfactory mucosa was carefully dissected into ice-cold media hormone mix (MHM) [66], washed twice in Hanks' Balanced Salt Solution (HBSS, calcium- and magnesium-free;
Invitrogen) and incubated for $20 \mathrm{~min}$ at $37^{\circ} \mathrm{C}$ in Dispase II (Boehringer Mannheim). The tissue was then digested in $0.5 \%$ collagenase type IA (Sigma-Aldrich) in MHM for $20 \mathrm{~min}$ at $37^{\circ} \mathrm{C}$ and mechanically dissociated. Cells were passed through an $80 \mu \mathrm{m}$ cell-strainer-mesh and resuspended in MHM.

\section{Primary OEC preparation}

The olfactory mucosa was treated as above with Dispase II and the superficial portion of the epithelium was shed off. The remaining tissue was collected in HBSS and centrifuged. The cell pellet was digested in $0.5 \%$ collagenase type IA in DMEM/F12 for $20 \mathrm{~min}$ at $37^{\circ} \mathrm{C}$ and dissociated. The cells were collected in DMEM/F12 +10\% fetal bovine serum (FBS), spun down, and resuspended in culture medium. The culture medium consisted of DMEM/F12 supplemented with 10\% FBS. Cells were fixed with $4 \%$ PFA for $10 \mathrm{~min}$ for immunostaining.

\section{Sphere forming cultures}

Olfactory mucosa cells were resuspended in MHM [66] supplemented with recombinant human EGF (100 ng/ $\mathrm{ml}$, Pepro Tech), recombinant human FGF-2 (100 ng/ ml, Pepro Tech), B27 supplement (Invitrogen), and Antibiotic-Antimycotic (Invitrogen). For clonal sphere formation, cells were plated at a density of $8.0 \times 10^{4}$ cells/well (6-well plates) in culture medium containing $1 \%$ methylcellulose. Spheres from CNS were prepared as described previously [67].

\section{Clonal analysis}

Each sphere was individually plated in a chamber of poly-D-lysin/laminin (Sigma-Aldrich/Invitrogen)-coated 8-well chamber slides (Iwaki) and cultured for 14 days in MHM supplemented with $10 \%$ FBS, without any growth factors. Differentiated cells were fixed with $4 \%$ PFA in PBS, boiled for $5 \mathrm{~min}$ to inactivate GFP-fluorescence, and pretreated with PBS containing 0.3\% Triton$\mathrm{X} 100$ for $5 \mathrm{~min}$ at room temperature before immunostaining. The samples were mounted and observed with a universal fluorescence microscope (Axioskop 2 Plus, Carl Zeiss).

\section{RT-PCR}

RNA was prepared using Trizol (Invitrogen) for primary $\mathrm{GFP}^{+}$cells sorted from the olfactory mucosa, and RNeasy mini kit (Qiagen) for the other samples. RNA was treated with RNase-free DNase and cDNA was generated using oligo (dT) primers and SuperScript II RT reverse transcriptase (Invitrogen) as directed by the manufacturer. The following primers were obtained from Takara: Snail1, MA030195; Snail2, MA030179; p75, MA004379; Pax3, MA026554; p0, MA026318; and Actb, MA023938. For detection of Sox9 and Sox10, 
primers were designed as follows: Sox9-F, 5'CAAGTGTG TGTGCCGTGGATAG-3'; Sox9-R, 5' CCAGCCACAGCAGTGAGTAAGAA-3'; Sox10-F, 5'ACGCACTGAGGACAGCTTTGA-3'; and Sox10-R, 5'ATGAGGTTA TTGACAGCTTTGA-3'.

\section{Flow-cytometric isolation of $\mathrm{GFP}^{+}$cells}

P0-Cre/Floxed-EGFP mice (postnatal 4 weeks) were killed and olfactory mucosa cells were collected as described above. Cells were stained with PI and subjected to flow-cytometry using Vantage (BD Biosciences) to sort out $\mathrm{GFP}^{+}$cells and eliminate $\mathrm{PI}^{+}$dead cells. Collected cells were immediately subjected to RNA preparation.

\section{Additional material}

\section{Additional file 1: PCR confirms Cre recombination in $\mathrm{GFP}^{+}$cells. a,}

Schematic diagrams of the CAG-CAT-EGFP transgene cassettes in the transgenic mice. The Cre recombinase excises the loxP-flanked CAT reporter gene resulting in GFP expression. The arrows under the gene constructs indicate the position and direction of the primers used for PCR. PA is a polyadenylation signal. The sizes of the PCR products are indicated under each gene construct. $\mathbf{b}$ Genomic PCR of GFP-positive or negative cells sorted from the olfactory mucosa of PO-Cre/Floxed-EGFP mice with the primer sets shown in a confirms Cre-mediated recombination in GFP $P^{+}$cells. The sequence of the primers are: CAGp F, 5'-CTGCTAACCATGTTCATGCC-3'; EGFP R1, 5'-TGGTGCAGATGAACTTCAGG3'; EGFP F, 5'-AGCACGACTTCTTCAAGTCC-3'; EGFP R2, 5'TGAAGTTCACCTTGATGCCG-3'.

Additional file 2: Clonal sphere culture in medium containing $1 \%$ methylcellulose. To determine cell density required for clonal culture, cells from the olfactory mucosa of GFP and RFP mice were equally mixed and cultured at a density of $8.0 \times 10^{4}$ cells or $1.6 \times 10^{5}$ cells per well in 6 -well plates. The culture medium contained $1 \%$ methylcellulose to inhibit sphere migration and fusion. a, Formed spheres. Most spheres were of a single color but a small percentage of spheres were mixed (2.3 $\pm 4.0 \%$ at $8.0 \times 10^{4}$ cells/well, $14.7 \pm 8.5 \%$ at $1.6 \times 10^{5}$ cells/well). $\mathbf{b}$ Percentage of single and mixed-color spheres. Values represent mean \pm $\operatorname{SD}(n=3)$.

\section{Abbreviations}

OE: olfactory epithelium; OEC: olfactory ensheathing cell; NC: neural crest; PO: protein zero; (E)GFP: (enhanced) green fluorescent protein; p75: p75 low affinity nerve growth factor receptor; PE: post-electroporation; $\mathrm{HBC}$ : horizontal basal cell; GBC: globose basal cell; SUS: sustentacular (cell); ORN: olfactory receptor neuron; CNS: central nervous system: GFAP: glial fibrillary acidic protein; EGF: epidermal growth factor; FGF: fibroblast growth factor; OM: olfactory mucosa; SMA: smooth muscle actin; PFA: paraformaldehyde; OCT: optimal cutting temperature; PBS: phosphate buffered saline; MHM: media hormone mix; DMEM: Dulbecco's Modified Eagle's Medium; FBS: fetal bovine serum.

\section{Acknowledgements}

We are grateful to members of the Okano laboratory, Keio University, and Dr. Yoshiko Takahashi for helpful advice and discussions. This work was supported by grants from Grants-in-Aid for Scientific Research from JSPS and the Ministry of Education, Culture, Sports, Science and Technology of Japan (MEXT), the project for realization of regenerative medicine and Support for the core institutes for IPS cell research from MEXT to M.N. and H.O., and "Funding Program for World-leading Innovative R\&D on Science and Technology" to H.O.

\section{Author details}

'Department of Orthopaedic Surgery, Keio University School of Medicine, 35 Shinanomachi, Shinjuku-ku, Tokyo, 160-8582, Japan. ${ }^{2}$ Department of Physiology, Keio University School of Medicine, 35 Shinanomachi, Shinjukuku, Tokyo, 160-8582, Japan. ${ }^{3}$ Department of Biological Science, Tokyo Metropolitan University, 1-1 Minami-Osawa, Hachioji-shi, Tokyo, 192-0397, Japan. ${ }^{4}$ Department of Gerontological Nursing/Wound Care Management, Graduate School of Medicine, The University of Tokyo, 7-3-1 Hongo, Bunkyoku, Tokyo, 113-0033, Japan. ${ }^{5}$ National Institute of Musculo-Skeletal Disorders, Murayama Medical Center, 2-37-1 Gakuen, Musashimurayama-shi, Tokyo, 208-0011, Japan. ${ }^{6}$ Department of Biophysics and Biochemistry, Graduate School of Health Sciences, Tokyo Medical and Dental University, 1-5-45 Yushima, Bunkyo-ku, Tokyo, 113-8519, Japan.

\section{Authors' contributions}

$H K, S S, N N, K F, E S, M S$, and TM performed the experiments. KF, ES, MS, and TM performed cell tracing studies in chick embryos. CA provided the Sox10Venus mice. YM supported all flow cytometry analyses. YK, AT, and YT participated in the preparation of this study. HK, SS, ES, MN, and HO wrote the manuscript. $\mathrm{HO}$ provided financial support for the experiments. All authors have read and approved the manuscript.

\section{Competing interests}

The authors declare that they have no competing interests.

Received: 11 August 2011 Accepted: 23 September 2011 Published: 23 September 2011

\section{References}

1. Le Douarin N: The Neural Crest Cambridge: Cambridge University Press; 1999.

2. Selleck MA, Scherson TY, Bronner-Fraser M: Origins of neural crest cell diversity. Developmental biology 1993, 159:1-11.

3. Klein SL, Graziadei PP: The differentiation of the olfactory placode in Xenopus laevis: a light and electron microscope study. J Comp Neurol 1983, 217:17-30

4. Mendoza AS, Breipohl W, Miragall F: Cell migration from the chick olfactory placode: a light and electron microscopic study. J Embryol Exp Morphol 1982, 69:47-59.

5. Couly GF, Le Douarin NM: Mapping of the early neural primordium in quail-chick chimeras. I. Developmental relationships between placodes, facial ectoderm, and prosencephalon. Developmental biology 1985, 110:422-439.

6. Burr HS: The effects of the removal of the nasal pits in Amblystoma embryos. J Exp Zool 1916, 20:27-57.

7. Osumi-Yamashita N, Kuratani S, Ninomiya Y, Aoki K, Iseki S, Chareonvit S, Doi H, Fujiwara M, Watanabe T, Eto K: Cranial anomaly of homozygous rSey rat is associated with a defect in the migration pathway of midbrain crest cells. Development, growth \& differentiation 1997, 39:53-67.

8. Bhasin N, Maynard TM, Gallagher PA, LaMantia AS: Mesenchymal/epithelial regulation of retinoic acid signaling in the olfactory placode. Developmental biology 2003, 261:82-98.

9. Echelard Y, Vassileva G, McMahon AP: Cis-acting regulatory sequences governing Wnt-1 expression in the developing mouse CNS. Development (Cambridge, England) 1994, 120:2213-2224.

10. Filbin MT, Walsh FS, Trapp BD, Pizzey JA, Tennekoon GI: Role of myelin PO protein as a homophilic adhesion molecule. Nature 1990, 344:871-872.

11. Filbin MT, Tennekoon Gl: Homophilic adhesion of the myelin PO protein requires glycosylation of both molecules in the homophilic pair. J Cell Biol 1993, 122:451-459.

12. Bhattacharyya A, Frank E, Ratner N, Brackenbury R: PO is an early marker of the Schwann cell lineage in chickens. Neuron 1991, 7:831-844.

13. Lee MJ, Calle E, Brennan A, Ahmed S, Sviderskaya E, Jessen KR, Mirsky R: In early development of the rat mRNA for the major myelin protein $\mathrm{P}(0)$ is expressed in nonsensory areas of the embryonic inner ear, notochord, enteric nervous system, and olfactory ensheathing cells. Dev Dyn 2001, 222:40-51

14. Kawamoto S, Niwa H, Tashiro F, Sano S, Kondoh G, Takeda J, Tabayashi K, Miyazaki J: A novel reporter mouse strain that expresses enhanced green fluorescent protein upon Cre-mediated recombination. FEBS Lett 2000, 470:263-268. 
15. Sato Y, Kasai T, Nakagawa S, Tanabe K, Watanabe T, Kawakami K, Takahashi Y: Stable integration and conditional expression of electroporated transgenes in chicken embryos. Developmental biology 2007, 305:616-624.

16. Chuah Ml, Au C: Olfactory Schwann cells are derived from precursor cells in the olfactory epithelium. J Neurosci Res 1991, 29:172-180.

17. Ramon-Cueto A, Avila J: Olfactory ensheathing glia: properties and function. Brain Res Bull 1998, 46:175-187.

18. Dymecki SM, Tomasiewicz H: Using Flp-recombinase to characterize expansion of Wnt1-expressing neural progenitors in the mouse. Developmental biology 1998, 201:57-65.

19. Matsuoka T, Ahlberg PE, Kessaris N, lannarelli P, Dennehy U, Richardson WD, McMahon AP, Koentges G: Neural crest origins of the neck and shoulder. Nature 2005, 436:347-355.

20. Danielian PS, Muccino D, Rowitch DH, Michael SK, McMahon AP: Modification of gene activity in mouse embryos in utero by a tamoxifen-inducible form of Cre recombinase. Curr Biol 1998, 8:1323-1326.

21. Yamauchi Y, Abe K, Mantani A, Hitoshi Y, Suzuki M, Osuzu F, Kuratani S, Yamamura K: A novel transgenic technique that allows specific marking of the neural crest cell lineage in mice. Developmental biology 1999, 212:191-203.

22. Yoshida S, Shimmura S, Nagoshi N, Fukuda K, Matsuzaki Y, Okano H, Tsubota K: Isolation of multipotent neural crest-derived stem cells from the adult mouse cornea. Stem cells (Dayton, Ohio) 2006, 24:2714-2722

23. Tomita Y, Matsumura K, Wakamatsu Y, Matsuzaki Y, Shibuya I, Kawaguchi H, leda M, Kanakubo S, Shimazaki T, Ogawa S, Osumi N, Okano H, Fukuda K: Cardiac neural crest cells contribute to the dormant multipotent stem cell in the mammalian heart. J Cell Biol 2005, 170:1135-1146.

24. Nagoshi N, Shibata S, Kubota Y, Nakamura M, Nagai Y, Satoh E, Morikawa S, Okada Y, Mabuchi Y, Katoh H, Okada S, Fukuda K, Suda T, Matsuzaki Y, Toyama Y, Okano H: Ontogeny and multipotency of neural crest-derived stem cells in mouse bone marrow, dorsal root ganglia, and whisker pad. Cell stem cell 2008, 2:392-403.

25. Asada N, Takase M, Nakamura J, Oguchi A, Asada M, Suzuki N, Yamamura K, Nagoshi N, Shibata S, Rao TN, Fehling HJ, Fukatsu A, Minegishi N, Kita T, Kimura T, Okano $H$, Yamamoto $M$, Yanagita M: Dysfunction of fibroblasts of extra-renal origin underlies renal fibrosis and renal anemia in mice. $J$ Clin Invest

26. Shibata S, Yasuda A, Renault-Mihara F, Suyama S, Katoh H, Inoue T, Inoue YU, Nagoshi N, Sato M, Nakamura M, Akazawa C, Okano H: Sox10Venus mice: a new tool for real-time labeling of neural crest lineage cells and oligodendrocytes. Mol Brain 2010, 3:31.

27. Le Douarin NM, Renaud D, Teillet MA, Le Douarin GH: Cholinergic differentiation of presumptive adrenergic neuroblasts in interspecific chimeras after heterotopic transplantations. Proceedings of the National Academy of Sciences of the United States of America 1975, 72:728-732.

28. Bronner-Fraser M, Sieber-Blum M, Cohen AM: Clonal analysis of the avian neural crest: migration and maturation of mixed neural crest clones injected into host chicken embryos. J Comp Neurol 1980, 193:423-434.

29. Kawakami K, Noda T: Transposition of the Tol2 element, an Ac-like element from the Japanese medaka fish Oryzias latipes, in mouse embryonic stem cells. Genetics 2004, 166:895-899.

30. Harada H, Takahashi Y, Kawakami K, Ogura T, Nakamura H: Tracing retinal fiber trajectory with a method of transposon-mediated genomic integration in chick embryo. Development, growth \& differentiation 2008, 50:697-702.

31. Del Barrio MG, Nieto MA: Relative expression of Slug, RhoB, and HNK-1 in the cranial neural crest of the early chicken embryo. Developmental dynamics: an official publication of the American Association of Anatomists 2004, 229:136-139.

32. Beites CL, Kawauchi S, Crocker CE, Calof AL: Identification and molecular regulation of neural stem cells in the olfactory epithelium. Experimental cell research 2005, 306:309-316.

33. Leung $C T$, Coulombe PA, Reed RR: Contribution of olfactory neural stem cells to tissue maintenance and regeneration. Nature neuroscience 2007, 10:720-726.

34. Doucette JR, Kiernan JA, Flumerfelt BA: The re-innervation of olfactory glomeruli following transection of primary olfactory axons in the central or peripheral nervous system. Journal of anatomy 1983, 137(Pt 1):1-19.
35. D'Amico-Martel A, Noden DM: Contributions of placodal and neural crest cells to avian cranial peripheral ganglia. The American journal of anatomy 1983, 166:445-468

36. Forni PE, Taylor-Burds C, Melvin S, Williams T, Wray S: Neural Crest and Ectodermal Cells Intermix in the Nasal Placode to give rise to $\mathrm{GnRH}-1$ Neurons, Sensory Neurons and Olfactory Ensheathing Cells. $J$ Neuroscience 2011, 31:6915-6927, Forni.PE, Taylor-Burds C, Melvin S, Williams T, Wray S: Neural Crest and Ectodermal Cells Intermix in the Nasal Placode to give rise to GnRH-1 Neurons, Sensory Neurons and Olfactory Ensheathing Cells. J. Neuroscience, 31:6915-27, 2011.

37. Toma JG, Akhavan M, Fernandes KJ, Barnabe-Heider F, Sadikot A, Kaplan DR Miller FD: Isolation of multipotent adult stem cells from the dermis of mammalian skin. Nat Cell Biol 2001, 3:778-784.

38. Amoh Y, Li L, Katsuoka K, Penman S, Hoffman RM: Multipotent nestinpositive, keratin-negative hair-follicle bulge stem cells can form neurons. Proceedings of the National Academy of Sciences of the United States of America 2005, 102:5530-5534

39. Kang SK, Putnam LA, Ylostalo J, Popescu IR, Dufour J, Belousov A, Bunnell BA: Neurogenesis of Rhesus adipose stromal cells. J Cell Sci 2004, 117:4289-4299

40. Roisen FJ, Klueber KM, Lu CL, Hatcher LM, Dozier A, Shields CB, Maguire S: Adult human olfactory stem cells. Brain research 2001, 890:11-22.

41. Murrell W, Feron F, Wetzig A, Cameron N, Splatt K, Bellette B, Bianco J, Perry C, Lee G, Mackay-Sim A: Multipotent stem cells from adult olfactory mucosa. Dev Dyn 2005, 233:496-515.

42. Nagoshi N, Shibata S, Hamanoue M, Mabuchi Y, Matsuzaki Y, Toyama Y, Nakamura M, Okano H: Schwann cell plasticity after spinal cord injury shown by neural crest lineage tracing. Glia 2011, 59:771-784.

43. Real C, Glavieux-Pardanaud C, Vaigot P, Le-Douarin N, Dupin E: The instability of the neural crest phenotypes: Schwann cells can differentiate into myofibroblasts. Int J Dev Biol 2005, 49:151-159.

44. Bixby S, Kruger GM, Mosher JT, Joseph NM, Morrison SJ: Cell-intrinsic differences between stem cells from different regions of the peripheral nervous system regulate the generation of neural diversity. Neuron 2002, 35:643-656.

45. Morrison SJ, White PM, Zock C, Anderson DJ: Prospective identification, isolation by flow cytometry, and in vivo self-renewal of multipotent mammalian neural crest stem cells. Cell 1999, 96:737-749.

46. Stemple DL, Anderson DJ: Isolation of a stem cell for neurons and glia from the mammalian neural crest. Cell 1992, 71:973-985.

47. Suzuki K, Tanaka M, Watanabe N, Saito S, Nonaka H, Miyajima A: p75 Neurotrophin receptor is a marker for precursors of stellate cells and portal fibroblasts in mouse fetal liver. Gastroenterology 2008, 135:270-281 e273.

48. Murdoch B, Roskams AJ: Olfactory epithelium progenitors: insights from transgenic mice and in vitro biology. J Mol Histol 2007, 38:581-599.

49. Britsch S, Goerich DE, Riethmacher D, Peirano RI, Rossner M, Nave KA, Birchmeier C, Wegner M: The transcription factor Sox10 is a key regulator of peripheral glial development. Genes Dev 2001, 15:66-78.

50. Paratore C, Goerich DE, Suter U, Wegner M, Sommer L: Survival and glial fate acquisition of neural crest cells are regulated by an interplay between the transcription factor Sox 10 and extrinsic combinatorial signaling. Development (Cambridge, England) 2001, 128:3949-3961.

51. Kuhlbrodt K, Herbarth B, Sock E, Hermans-Borgmeyer I, Wegner M: Sox10, a novel transcriptional modulator in glial cells. J Neurosci 1998, 18:237-250.

52. Carter LA, MacDonald JL, Roskams AJ: Olfactory horizontal basal cells demonstrate a conserved multipotent progenitor phenotype. J Neurosci 2004, 24:5670-5683.

53. Takashima Y, Era T, Nakao K, Kondo S, Kasuga M, Smith AG, Nishikawa S: Neuroepithelial cells supply an initial transient wave of MSC differentiation. Cell 2007, 129:1377-1388.

54. Morikawa S, Mabuchi Y, Niibe K, Suzuki S, Nagoshi N, Sunabori T, Shimmura S, Nagai Y, Nakagawa T, Okano H, Matsuzaki Y: Development of mesenchymal stem cells partially originate from the neural crest. Biochem Biophys Res Commun 2009, 379:1114-1119.

55. Dupin E, Sextier-Sainte-Claire Deville F, Nataf V, Le Douarin NM: The ontogeny of the neural crest. C R Acad Sci III 1993, 316:1062-1081.

56. Kocsis JD, Lankford KL, Sasaki M, Radtke C: Unique in vivo properties of olfactory ensheathing cells that may contribute to neural repair and protection following spinal cord injury. Neurosci Lett 2009, 456:137-142. 
57. Mackay-Sim A, St John JA: Olfactory ensheathing cells from the nose: clinical application in human spinal cord injuries. Experimental neurology 2011, 229:174-180.

58. Li L, Mignone J, Yang M, Matic M, Penman S, Enikolopov G, Hoffman RM: Nestin expression in hair follicle sheath progenitor cells. Proceedings of the National Academy of Sciences of the United States of America 2003, 100:9958-9961.

59. Amoh Y, Kanoh M, Niiyama S, Kawahara K, Sato Y, Katsuoka K, Hoffman RM: Human and mouse hair follicles contain both multipotent and monopotent stem cells. Cell Cycle 2009, 8:176-177.

60. Uchugonova A, Hoffman RM, Weinigel $\mathrm{M}$, Koenig $\mathrm{K}$ : Watching stem cells in the skin of living mice noninvasively. Cell Cycle 2011, 10:2017-2020.

61. Uchugonova A, Duong J, Zhang N, Konig K, Hoffman RM: The bulge area is the origin of nestin-expressing pluripotent stem cells of the hair follicle. J Cell Biochem 2011, 112:2046-2050.

62. Amoh Y, Li L, Campillo R, Kawahara K, Katsuoka K, Penman S, Hoffman RM: Implanted hair follicle stem cells form Schwann cells that support repair of severed peripheral nerves. Proceedings of the National Academy of Sciences of the United States of America 2005, 102:17734-17738.

63. Amoh Y, Li L, Katsuoka K, Hoffman RM: Multipotent hair follicle stem cells promote repair of spinal cord injury and recovery of walking function. Cell Cycle 2008, 7:1865-1869.

64. Liu F, Uchugonova A, Kimura H, Zhang C, Zhao M, Zhang L, Koenig K, Duong J, Aki R, Saito N, Mii S, Amoh Y, Katsuoka K, Hoffman RM: The bulge area is the major hair follicle source of nestin-expressing pluripotent stem cells which can repair the spinal cord compared to the dermal papilla. Cell Cycle 2011, 10:830-839.

65. Hamburger V, Hamilton HL: A series of normal stages in the development of the chick embryo. 1951. Dev Dyn 1992, 195:231-272.

66. Okada Y, Shimazaki T, Sobue G, Okano H: Retinoic-acid-concentrationdependent acquisition of neural cell identity during in vitro differentiation of mouse embryonic stem cells. Developmental biology 2004, 275:124-142.

67. Vescovi AL, Reynolds BA, Fraser DD, Weiss S: bFGF regulates the proliferative fate of unipotent (neuronal) and bipotent (neuronal/ astroglial) EGF-generated CNS progenitor cells. Neuron 1993, 11:951-966.

doi:10.1186/1756-6606-4-34

Cite this article as: Katoh et al:: The dual origin of the peripheral olfactory system: placode and neural crest. Molecular Brain 2011 4:34.

\section{Submit your next manuscript to BioMed Central and take full advantage of:}

- Convenient online submission

- Thorough peer review

- No space constraints or color figure charges

- Immediate publication on acceptance

- Inclusion in PubMed, CAS, Scopus and Google Scholar

- Research which is freely available for redistribution 